\title{
Factors Influencing the Adoption Intention of Blockchain and Internet-of- Things Technologies for Sustainable Blood Bank Management
}

Sachin Kuberkar, Symbiosis Centre for Management Studies (SCMS), Symbiosis International University (Deemed), Pune, India

iD https://orcid.org/0000-0003-3661-2204

Tarun Kumar Singhal, Symbiosis Centre for Management Studies (SCMS), Symbiosis International University (Deemed), Pune, India

iD https://orcid.org/0000-0002-5929-183X

\begin{abstract}
Owing chiefly to the lack of suitable technology solutions, India is experiencing both a shortage and wastage of blood units. In addressing such a challenge, the authors explore the unique role of blockchain and internet-of-things technologies in the overall blood supply chain management as an appropriate technology solution. The study employs an integrated task-technology fit and technology acceptance model to empirically test and identify key factors influencing the adoption intention of the blockchain and internet-of-things-enabled system. With the need to preserve donor and recipient data integrity and data privacy, the respective state and national health departments strictly regulate blood banks. Accordingly, the study also explores the role of government in supporting and overseeing security concerns in the future adoption of the blockchain and internet-of-things technologies. Finally, a solution based on the blockchain and internet-of-things technologies to ensure the sufficient availability of blood units at the national level is envisioned.
\end{abstract}

\section{KEYWORDS}

Blockchain (BC), Blood Bank Management (BBM), Internet of Things (IoT), Task-Technology Fit (TTF), Technology Acceptance Model (TAM)

\section{INTRODUCTION}

Human blood is highly perishable. As blood is transfused from one person to another and cannot be created synthetically, it often will be short in supply but high in demands (Boonyanusith \& Jittamai, 2017). In an equitable and modern healthcare system, the World Health Organization (WHO) recommends a seamless blood supply chain (SC) at the national level to reduce child mortality, prevent infections, and improve overall health and wellbeing of a country's citizens (WHO, 2016; Pal, Kar, Zaman, \& Pal, 2011). As well, WHO (2008) recommends that to avail blood products to patients on-demand, a country's blood ecosystem should ensure that throughout the lifecycle, these 
blood products remain safe; therefore, a critical aspect of the social wellbeing of any society, is the systematic management of the blood SC.

Accordingly, all of the blood SC stakeholders in a country such as blood banks, hospitals, healthcare service providers, government agencies, and citizens should unite to meet its overall blood demand (NACO, 2016). A lack of coordination among any of the stakeholders can lead to blood shortage, sometimes even transfusion-related diseases (Nanu, 2001). In India, managing the blood SC is often challenged with multiple complications (GOI, 2003). Specifically, blood banks play a critical role in the overall blood SC by matching the supply-demand volumes (Lowalekar \& Ravichandran, 2014). In 2017, among 2,903 blood banks in India, about 11 million units of blood (lesser than the annual target of 13 million units) were cumulatively collected during the year (DOHFW, 2018), while over 1 million units had ultimately to be discarded due to reasons such as storage date expiry and/or deterioration, blood infections and donor reactions (NACO, 2017), averaging in an annual shortfall of 3 million units. Another issue with India's blood SC is that about thirty-four percent (34\%) of these blood banks operate without a license (Pal et al., 2011), thereby incurring a high risk of noncompliance while posing a severe threat to the patient's life.

While some blood banks have a preliminary Blood Bank Management Information System (BBMIS) to manage the staff activities and inventory updates (Sulaiman, Hamid \& Yusri, 2015), however, apart from poor coordination among multiple blood-bank stakeholders (NACO, 2016), there has been a general lack of adopting emerging technologies such as Blockchain and Internet-of-Things (IoT) to address the challenges faced in blood-bank SC. As this has been identified as one of the critical factors for blood wastage (Lowalekar \& Ravi, 2017) in India, a theoretical model is urgently needed to better understand the adoption of such technologies. Here, we attempt to address the key research question: What factors affect the adoption intention of Blockchain and IoT technologies in blood bank management?

The organization of the rest of this paper is as follows. In Section 2, we detail background information via a comprehensive review of the extant literature on BBMIS, IoT and Blockchain. Following this, in Section 3, an integrated framework based on key constructs drawn from the TaskTechnology Fit (TTF) and Technology Acceptance Model (TAM), along with other crucial concepts such as Government Support and Security Concerns, is proposed as a preliminary theoretical approach towards hypotheses development for this study. Section 4 then shifts focus to research methodology, where concepts such as measures, research instrumentation, sampling and data collection as well as response and method bias are highlighted. Attention on the statistical modeling and results is directed then to Section 5 whereas Section 6 discusses the logical interpretations and practical implications of these findings. Finally, concluding remarks with insights on the study limitations and future works are also provided at the end of Section 7.

\section{BACKGROUND}

Owing primarily to the short shelf life and varied supply-demand frequency of blood products (Boonyanusith \& Jittamai, 2017; Pierskalla, 2005), the literature on perishable items SC classifies blood supply chain management (SCM) as a complex management problem. Attention to these problems have now generated studies that highlight how the Blockchain and the IoT technologies could have assisted in the efficient management of the perishable item SC (Queiroz \& Wamba, 2019; Clauson, Breeden, Davidson \& Mackey, 2018; Ben-Daya, Hassini \& Bahroun, 2017; Biswas, Muthukkumarasamy \& Tan, 2017; Dada \& Thiesse, 2008; Verdouw, Wolfert, Beulens \& Rialland, 2016). Among these works, Boonyanusith \& Jittamai (2017) and Abarca, De la Fuente, Abril, García \& Pérez-Ocón (2009) recommended IoT-based solutions for several blood bank activities such as inventory management and transportation monitoring. Jayaraman, Saleh \& King (2019), Peltoniemi \& Ihalainen (2019), and Clauson et al. (2018) conceptualized a Blockchain and IoT solution for tracking products in the healthcare SC, reducing systemic errors and redundant efforts. 
Notwithstanding, the adoption of Blockchain and IoT technologies in the context of blood bank management remains scarcely investigated. In the following sections, we divide the literature review into three subparts: (a) BBMIS; (b) IoT; and (c) Blockchain.

\subsection{Blood-Bank Management Information System (BBMIS)}

From a public health perspective, the government's role is to ensure safe, sustainable, and on-time delivery of blood units to those patients who may be in need of blood transfusion (Ramani, Mavalankar \& Govil, 2007). The WHO recommends a standardized blood management system for national-level coordination among stakeholders that encourages strict adherence to the highest safety standards and quality benchmarks (WHO, 2011). Not surprisingly, prior research highlights that information systems (IS) can play a premier role in implementing such national-level public health initiatives (Heeks, 2001).

To date, a growing body of the extant literature focuses on the adoption of BBMIS for the blood bank's daily operations (Pietersz, 1995; Raj \& Tarun, 1991; Farmer, 1982). With worldwide diffusion of Internet technology, Wong (2011) recommended a web-based BBMIS for real-time visibility and ordering of blood products. Arif, Sreevas, Nafseer \& Rahul (2012) suggested additional improvements to online BBMIS, such as the automated call routing facility, to fulfill blood requirements ondemand. Blood and blood components require preservation in the cold storage facility at a specific temperature range before their eventual expiry (Hess, 2010). As the usable life expectancy of stored blood can be significantly affected by storage conditions, a sensor-based temperature control system is recommended to alert staff physically present in the blood bank facility in the event of adverse temperature fluctuations (U.S. Patent No. 4,441,329, 1984).

\subsection{Internet-of-Things (loT)}

IoT, a term coined by Kevin Ashton in 1999 (Ashton, 2009), play an instrumental role in the expanding connectivity of sensor-automated and intelligent devices (Gubbi, Buyya, Marusic \& Palaniswami, 2013). Briefly, IoT technology connects sensor-embedded physical devices to the internet for the remote management and monitoring of such devices in real-time (Peoples, Parr, McClean, Scotney \& Morrow, 2013). Led by price decline, device miniaturization and the evolving availability of high-speed internet, the IoT devices are being increasingly applied in the end-to-end SCM of various kinds of products, especially the perishable items (Gao \& Bai, 2014). These IoT devices tackle key $\mathrm{SC}$ challenges such as shrinkage and wastage. The use of IoT technology also enhances contract execution between SC business partners (Dada \& Thiesse, 2008).

With IoT technology in place, physical objects can now transmit their real-time surrounding conditions and location information to a remotely connected server via what is commonly known as the internet protocol (Alemdar \& Ersoy, 2010). As an example, a sensor can provide temperature information of a milk pack inside a fridge to the owner's internet-connected smartphone in real-time (Welbourne et al., 2009). Weber (2009) has defined IoT as an emerging information technology (IT) for the SCs using the standards of the domain name system. Shih \& Wang (2016) studied coldchain management practices and proposed an IoT temperature indicator with wireless connectivity throughout the goods delivery process. Davis, Geiger, Gutierrez, Heaser \& Veeramani (2009) explored RFID tags for blood bank operations. Xu, Lian \& Yao (2013) studied it for inventory management. Hohberger, Davis, Briggs, Gutierrez \& Veeramani (2012) and Briggs et al. (2009) investigated IoT applications from the product's quality and safety point of view.

\subsection{Blockchain}

Blockchain is another emerging technology that was conceptualized by someone with a pseudo name, Satoshi Nakamoto, around the 2008 financial crisis (Nakamoto, 2008). In a peer-to-peer fashion, Blockchain comprises a network of participants where all participants share identical, immutable and time-stamped information via distributed consensus algorithms without the necessity of any centralized authority (Batubara, Ubacht \& Janssen, 2018). The chain of transaction blocks is linked 
via cryptography with the shared data features of the Blockchain becoming valuable characteristics in situations where quick decision-making has to be executed among multiple unknown parties (Turk $\&$ Klinc, 2017). A study by Ølnes, Ubacht \& Janssen (2017) projects Blockchain to lead to increased citizen trust and reduced corruption in governmental services.

Tse, Zhang, Yang, Cheng \& Mu (2017) and Tian (2016) studied Blockchain for the perishable items SC to meet the adequate quality and safety standards. Apte \& Petrovsky (2016) suggested that the transparency offered by the Blockchain network could be beneficial in the pharmaceutical SC for faster and more reliable movement tracking of medical supplies. Ahram, Sargolzaei, Sargolzaei, Daniels \& Amaba (2017) studied Blockchain application in the healthcare services to improve the integrity of patients' e-health records. Jayaraman et al. (2019) proposed an IoT- Blockchain solution that brings disparate players together in the healthcare SC for higher operational efficiency. Similarly, Düdder \& Ross (2017) explored Blockchain for SC information security.

\section{THEORETICAL FRAMEWORK AND HYPOTHESES DEVELOPMENT}

In Figure 1, a conceptual model based on our review of the extant literature relating to identifying key factors influencing the adoption intention of Blockchain and IoT for BBMIS is proposed.

Figure 1. Conceptual Framework

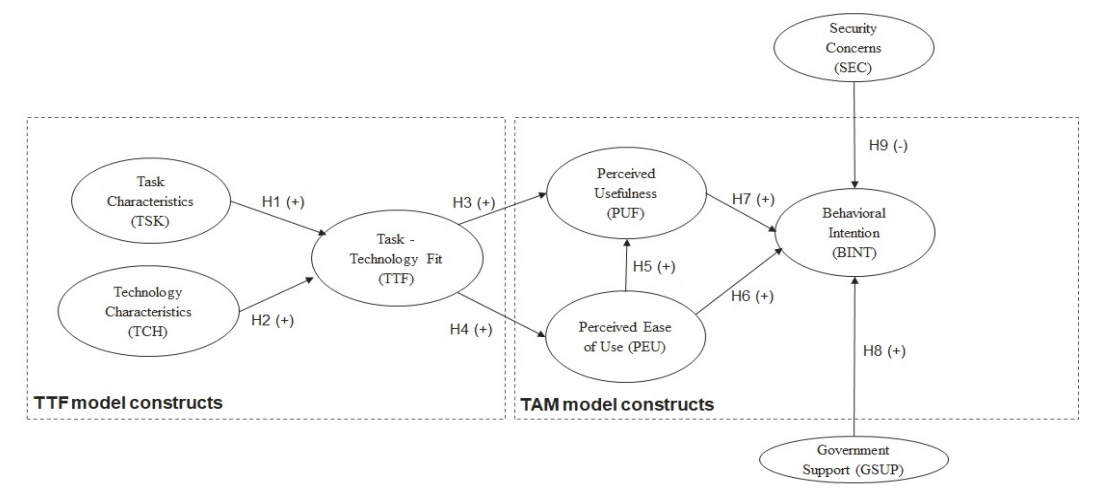

Two underlying theories as discussed below provide the key constructs being adapted and detailed in this theoretical framework. First, the Task-Technology Fit (TTF) theory infers that task characteristics (TSK) and technology characteristics (TCH) are key predictors of TTF (Goodhue \& Thompson, 1995). Moreover, according to Chen (2019), the TTF construct is considered a predictor for perceived usefulness (PUF) and perceived ease of use (PEU). Second, it is from the Technology Adoption Models (TAM) where the two constructs of PUF and PEU, which have been identified as predictors of Behavioral Intention (BINT), have been theoretically derived (Davis, 1989). In the following sections, the historical development of both these theories will now be highlighted.

\subsection{Technology Adoption Models (TAM)}

Over the years, researchers have studied the determinants of technology adoption behavior extensively (Chen, 2019; Adams, Nelson \& Todd, 1992; Davis 1989). Rapid innovations in IT have significantly attracted many researchers to explore factors behind adoption intention and actual usage of technologyled solutions (Queiroz \& Wamba, 2019). Introduced by Fishbein \& Ajzen (1980), the seminal theory 
of reasoned actions (TRA), followed by Ajzen's (1985) theory of planned behavior (TPB) formed the basis in measuring the adoption intention of IT solutions. Drawing on TRA and TPB, Davis (1989) proposed TAM to measure adoption intention and the subsequent use of IT solutions (Venkatesh \& Davis, 2000; Queiroz \& Wamba, 2019). TAM theorizes that PEU and PUF will impact the user's adoption behavior - a prediction that would consistently be validated when measuring users' attitudes towards IT-led solutions over the years (Chen, 2019).

\subsection{Task-Technology Fit (TTF)}

Even so, some researchers noted that using only the TAM places limitations in explaining adoption behavior as it does not provide enough insights for practitioners to implement the findings (Lee, Kozar \& Larsen, 2003). PUF and PEU of TAM only measure the users' attitudes towards IT-led solutions but do not explain the reasons behind PUF and PEU. Hence, researchers recommended employing TAM with other relevant constructs to improve its reasoning power (Cho, 2017; Gao \& Bai, 2014; Karahanna \& Straub, 1999; Koufaris, 2002; Venkatesh \& Davis, 2000).

The TTF theory, as proposed by Goodhue \& Thompson (1995), measure the suitability of the technology characteristics (TCH) with the task characteristics (TSK) to determines the performance impact and the utilization of technology (Erskine, Gregg, Karimi \& Scott, 2019; Sinha, Kumar, Rana, Islam \& Dwivedi, 2019; Wu and Chen, 2017). The TTF model's performance impacts the construct maps to PUF of TAM while the technology utilization construct of TTF maps to PEU of TAM, respectively (Dishaw \& Strong, 1999). In this sense, an integrated TTF-TAM framework would yield a better explanatory power for examining users' behavioral intentions towards their current or future IT adoption (Lee \& Lehto, 2013; Ma, Chao \& Cheng, 2013). Hence, the current study chooses to employ an integrated TTF-TAM framework.

\subsection{Hypotheses Development}

As our study also includes Government Support (GSUP) and Security Concerns (SEC) to be additional key factors influencing BINT while both GSUP and SEC are not covered under the integrated TTFTAM framework but could, in fact, play a crucial role in determining IT adoption behavior amongst government-regulated online services (Scupola, 2003), we have purposely added these two constructs to our proposed theoretical framework.

First, the government in India regulates blood bank operations; hence, we argue that the GSUP construct should be considered as a direct predictor of BINT (Taylor et al., 2005). Rationalizing along the same line, SEC may be viewed as a direct predictor of BINT as both the Blockchain and the IoT are internet-based technologies (McCole, Ramsey \& Williams, 2010).

Hypotheses formulation includes:

- $\quad$ Relationship between TSK \& TTF - Tasks are the activities that process specific inputs, producing desired outputs. TSK characteristics are influenced by IT (Goodhue \& Thompson, 1995); as well, unequivocal tasks having interdependence can be fit for technology use (Chen, 2019; Wu \& Chen, 2017). Blood bank TSK such as blood storage, audit, and inter-department coordination are expected to be fitting for technological assistance in delivering blood to needy patients. Past research shows TSK positively influences TTF (Chang, Lee \& Ji, 2016; Ma et al., 2013; Yen, Wu, Cheng \& Huang, 2010).

o Hypothesis H1: TSK has a positive influence on TTF.

- $\quad$ Relationship between TCH \& TTF - Users carry out their organizational tasks via some form of technology tools. TCH are those characteristics that contribute to the completion of tasks efficiently (Goodhue \& Thompson, 1995). TCH, such as accuracy, compatibility, currency, and reliability, makes the technology attractive for users to adopt it for their tasks (Ma et al., 2013). We assume here that Blockchain and IoT technologies can assist blood-bank stakeholders. Past 
studies show that TCH positively affects TTF (Chang et al., 2016; Chen, 2019; Wu \& Chen, 2017; Yen et al., 2010).

o Hypothesis H2: TCH has a positive effect on TTF.

- $\quad$ Relationship between TTF \& PUF and TTF \& PEU - TTF is a measure that evaluates IT suitability with task requirements (Goodhue \& Thompson, 1995). Briefly, TTF measures IT appropriateness for a given set of tasks. A good TTF will assist users in understanding whether the IT is beneficial and effortless to carry out the tasks (Chen, 2019; Dishaw \& Strong, 1999). Within the context of Blockchain and IoT enabled BBMIS, TTF may positively affect PUF and PEU. Results from past research indicates that TTF directly affects PUF and PEU (Chang et al., 2016; Wu \& Chen, 2017).

o Hypothesis H3: TTF has a positive impact on PUF.

o Hypothesis H4: TTF positively affects PEU.

- Relationship between PEU \& PUF and PEU \& BINT - PEU measures an individual's perception of technology as an effortless intervention (Davis, 1989). TAM posits that PEU affects both PUF and BINT (Chen, 2019). Within the blood bank context, PEU of Blockchain and IoT enabled BBMIS is expected to favorably impact PUF of blood bank stakeholders and BINT to adopt such a system. Several previous studies have also shown that PEU positively influences both PUF and BINT (Hong, Suh, \& Kim, 2009; Wu \& Zhang, 2014).

o Hypothesis H5: PEU has a positive influence on PUF.

o Hypothesis H6: PEU has a positive effect on BINT.

- $\quad$ Relationship between PUF \& BINT - PUF measures an individual's perception of a technology system as a performance enhancement tool (Davis, 1989). TAM posits that users tend to adopt an IT solution only if they believe that the solution is convenient in carrying out their job more efficiently (Ma et al., 2013). In blood bank, Blockchain-IoT enabled BBMIS's PUF may influence blood bank stakeholder's BINT to adopt such a system. Past studies have shown that PUF positively affects BINT (Alraimi, Zo \& Ciganek, 2015; Chang et al., 2016; Lee, Hsieh, \& Chen, 2013).

o Hypothesis H7: PUF positively affects BINT.

- $\quad$ Relationship between GSUP \& BINT - GSUP is an essential determinant of novel IT adoption in a highly regulated industry such as healthcare and blood banks. GSUP, in the form of government's policies and regulations, can influence the BINT of innovative solutions (Scupola, 2003; Tornatzky, Fleischer \& Chakrabarti, 1990). The government can support IT adoption by making appropriate changes to reporting and auditing norms as per newer IT capabilities (Lin \& Ho, 2008). In health care, the government can play a constructive role by formulating standards, setting up a network, and incentivizing stakeholders to adopt the innovative IT solutions (Taylor et al., 2005). Past Studies have shown GSUP positively affects BINT (Chiu, Chen \& Chen, 2017; Lian, Yen \& Wang, 2014; Lin \& Ho, 2008; Luthra, Kumar, Kumar \& Haleem, 2011; Rowe, Truex \& Huynh, 2012).

o Hypothesis H8: GSUP has a positive effect on BINT.

- $\quad$ Relationship between SEC \& BINT - SEC measures an individual's perception of technology being secure from external unauthorized access (Herath \& Rao, 2009). IoT adoption is constrained due to a perceived lack of security that may expose devices to external attacks and data breaches (Hsu \& Yeh, 2017). Similarly, security concerns such as a 51\% attack or stealing of cryptographic keys within the Blockchain network need to be addressed appropriately before implementing the solution (Lin \& Liao, 2017). Past studies have shown security concerns negatively impact BINT (Grabner-Krauter \& Kaluscha, 2003; McCole et al., 2010).

o Hypothesis H9: SEC has a negative effect on BINT. 


\section{RESEARCH METHODOLOGY}

\subsection{Measures}

Our conceptual framework combines TTF-TAM theoretical constructs along with GSUP and SEC to measure the BINT for Blockchain, and IoT enabled BBMIS. A survey was conducted in both online and offline mode for the primary data collection to validate the research hypotheses.

\subsection{Research Instrument}

The study employed a survey questionnaire that is recommended in prior research based on integrated TTF-TAM frameworks (Ma et al., 2013). The model constructs were measured on the 5-point Likert scale, and the scale's validity was established based on recommendations from MacKenzie, Podsakoff $\&$ Podsakoff (2011). The survey questions were formulated to gather the respondent's perception towards the Blockchain and IoT enabled BBMIS for their blood bank related tasks.

\subsection{Sampling and Data Collection}

Initially, the survey was submitted to five blood bank subject-matter experts to validate the data collection instrument. Post validation, a pilot test was conducted among 25 respondents by distributing the validated questionnaire. Based on the pilot results, the questionnaire was then shared with larger samples for the primary data collection. Even after a decade of their emergence, both the Blockchain and the IoT technologies are still nascent in terms of their technological maturity. Hence, a brief overview of these technologies was shared with the respondents to educate them about these technologies.

Partial least square-structural equation modeling (PLS-SEM) technique was deployed to analyze the data. The authors have followed the standard rule of having ten times the number of items in the survey questionnaire to ascertain the sample size (Gefen, Straub \& Boudreau, 2000). Hence, the study entailed a minimum sample size of 210. Table 1 shows the operationalization of constructs adapted for this study.

The questionnaire was distributed amongst hospitals and blood banks in Pune metropolitan region of India, covering 372 blood bank staff members, doctors, and nurses involved in blood transfusion activities. The researchers ensured that the respondents were part of the blood SC and were responsible either for the sourcing, managing, or transfusing of the blood units.

Calculating outer item loading and composite reliability underlined the testing of the construct's measurement reliability. Average Variance Extracted (AVE) was calculated to test the convergent validity. The constructs' internal consistency and reliability were measured via Cronbach's alpha.

\subsection{Response and Method Bias}

When some of the respondents did not respond to the survey, it might result in non-response bias due to the absence of data (Menachemi, 2011). This kind of bias may prevent the researchers from generalizing the findings of their research (Michie \& Marteau, 1999). Hence, it was necessary to treat non-response bias during the data analysis (Lewis, Hardy \& Snaith, 2013).

Accordingly, we have taken appropriate steps to ensure results were not affected by non-response bias. The data set separation technique was employed to tackle non-response bias by performing the t-test wave analysis of early and late respondents (Armstrong \& Overton, 1977). An insignificant difference $(p=0.48)$ was observed between the initial and last set of respondents. The researchers also deployed the single-factor Harman test to verify common method bias (Mackenzie \& Podsakoff, 2012). The analysis showed that no factor crossed the fifty percent (50\%) variance limit and thus we can safely note that the analytic finding free from common method bias. 
Table 1. Operationalization of model constructs

\begin{tabular}{|c|c|c|c|}
\hline Main constructs & $\begin{array}{c}\text { Construct } \\
\text { Type }\end{array}$ & Measures & Reference \\
\hline TSK & Reflective & $\begin{array}{l}\text { TSK1 - I usually find ill-defined problems when carrying } \\
\text { out blood bank tasks. } \\
\text { TSK2 - The blood bank related tasks usually involve more } \\
\text { than one business entity. }\end{array}$ & $\begin{array}{l}\text { Chen (2019), Wu } \\
\text { \& Chen (2017) }\end{array}$ \\
\hline $\mathrm{TCH}$ & Reflective & $\begin{array}{l}\text { TCH1 - The Blockchain and IoT enabled BBMIS will } \\
\text { provide accurate blood units storage information } \\
\text { TCH2 - The Blockchain and IoT enabled BBMIS will } \\
\text { help in faster tracking and tracing of blood units } \\
\text { TCH3 - The Blockchain and IoT enabled BBMIS will } \\
\text { remove the dependency on single data storage }\end{array}$ & $\begin{array}{l}\text { Chen (2019), Wu } \\
\text { \& Chen (2017) }\end{array}$ \\
\hline TTF & Reflective & $\begin{array}{l}\text { TTF1 - IoT, and Blockchain technologies are fit for blood } \\
\text { bank operations. } \\
\text { TTF2 - Blockchain and IoT technologies will always } \\
\text { provide real-time data. } \\
\text { TTF3 - Blockchain and IoT technologies will be } \\
\text { compatible with blood bank operations. }\end{array}$ & $\begin{array}{l}\text { Chen (2019), Wu } \\
\text { \& Chen (2017) }\end{array}$ \\
\hline PUF & Reflective & $\begin{array}{l}\text { PUF1 - I believe Blockchain and IoT enabled BBMIS } \\
\text { will improve performance. } \\
\text { PUF2 - I believe Blockchain and IoT enabled BBMIS will } \\
\text { improve effectiveness. }\end{array}$ & $\begin{array}{l}\text { Ma et al. (2013), } \\
\text { Yen et al. (2010) }\end{array}$ \\
\hline PEU & Reflective & $\begin{array}{l}\text { PEU1 - Blockchain and IoT enabled BBMIS will be easy } \\
\text { to learn. } \\
\text { PEU2 - Blockchain and IoT enabled BBMIS will be clear } \\
\text { and understandable. } \\
\text { PEU3 - Blockchain and IoT enabled BBMIS will be easy } \\
\text { to use. }\end{array}$ & $\begin{array}{l}\text { Ma et al. (2013), } \\
\text { Yen et al. (2010) }\end{array}$ \\
\hline SEC & Reflective & $\begin{array}{l}\text { SEC1 - I think Blockchain and IoT enabled BBMIS will } \\
\text { protect information before I can use it. } \\
\text { SEC2 - I think Blockchain and IoT enabled BBMIS will } \\
\text { provide a safer data sharing mechanism before I can use } \\
\text { it. } \\
\text { SEC3 - I think Blockchain and IoT enabled BBMIS will } \\
\text { build confidence in the system before I can use it. }\end{array}$ & $\begin{array}{l}\text { Rahi \& Abd. Ghani } \\
(2018) \text {, Enaizan et } \\
\text { al. (2018) }\end{array}$ \\
\hline GSUP & Reflective & $\begin{array}{l}\text { GSUP1 - Government will modify regulation needed to } \\
\text { adopt Blockchain and IoT enabled BBMIS. } \\
\text { GSUP2 - Government encouragement needed for blood } \\
\text { banks to move from paper based to Blockchain and IoT } \\
\text { based BBMIS. }\end{array}$ & $\begin{array}{l}\text { Chiu et al. (2017), } \\
\text { Lian et al. (2014) }\end{array}$ \\
\hline BINT & Reflective & $\begin{array}{l}\text { BI1 - Assuming, I have access, I intend to use Blockchain } \\
\text { and IoT enabled BBMIS. } \\
\text { BI2 - Compare to the current way, I will use Blockchain } \\
\text { and IoT enabled BBMIS. } \\
\text { BI3 - I will keep on using Blockchain and IoT enabled } \\
\text { BBMIS when implemented. }\end{array}$ & $\begin{array}{l}\text { Ma et al. (2013), } \\
\text { Yen et al. (2010) }\end{array}$ \\
\hline
\end{tabular}

\section{RESULTS}

The researchers reached out to key stakeholders of blood banks for this study. Table 2 shows the demographic profile of the survey respondents. While demographic data is collected as part of the survey to ensure the eligibility of respondents, no significant changes had been found in the results with respect to differences in age, gender, role, or work location of respondents within the study. 
Table 2. Table of demographics

\begin{tabular}{|l|l|l|l|}
\hline \multicolumn{1}{|c|}{ Demographic } & \multicolumn{1}{c|}{ Characteristics } & \multicolumn{1}{c|}{ Frequency } & \multicolumn{1}{c|}{ (\%) } \\
\hline Work Location & Blood Bank & 71 & 19 \\
\hline & Hospital & 186 & 50 \\
\hline & Health Institute & 93 & 25 \\
\hline & Clinic & 22 & 06 \\
\hline Gender & Male & 256 & 69 \\
\hline & Female & 116 & 31 \\
\hline Age & $21-30$ & 115 & 31 \\
\hline & $31-40$ & 163 & 44 \\
\hline & $41-50$ & 48 & 13 \\
\hline & $51-60$ & 46 & 12 \\
\hline
\end{tabular}

The insignificance of these variables is expected in the current study as the Blockchain and IoT technologies are emerging and not as yet implemented throughout India.

\subsection{PLS-SEM}

As noted, the PLS-SEM path modeling technique was deployed to analyze the data and to study the latent variables in this research. Gudergan, Ringle, Wende \& Will (2008) recommended the PLSSEM technique for conceptual model validation and relationship analysis between observed and latent variables. PLS-SEM modeling has also been applied in the past by other researchers to test an existing theory as it provides more flexibility in terms of construct modeling (Hair, Ringle \& Sarstedt, 2011; Henseler, 2010). SmartPLS software was applied for performing the PLS-SEM technique in this work (Ringle, Wende \& Will, 2005).

\subsection{Measurement Model}

The hypotheses testing for the conceptual model is based on the measurement of multi-item reflective constructs. According to Hair et al. (2006), the AVE may be calculated for testing the convergent validity of model constructs. In the current study, AVE had been observed to be more than the minimum value of 0.5 for all model constructs. Composite Reliability (CR) for constructs had been calculated for reflective measurement. The high values of CR indicated internal consistency. Drawing from the work of Nunnally (1978), the reliability of constructs is established by examining that the Cronbach's alpha value of constructs would be greater than 0.7 (see Table 3).

Additionally, the discriminant validity of research constructs had been examined via the FornellLarcker criterion. Off-diagonal values were computed (see Table 4) to verify discriminant validity and the correlation between the constructs. AVE is compared with the construct's inter-correlation to find out discriminant validity. The shared variance values were found to be lesser than the square root of AVE, which confirmed that the research constructs had discriminant validity (Fornell \& Larcker, 1981). 
Table 3. Construct measurement validity

\begin{tabular}{|l|l|l|l|}
\hline \multicolumn{1}{|c|}{ Construct } & $\begin{array}{c}\text { Average Variance Extracted } \\
\text { (AVE) }\end{array}$ & \multicolumn{1}{c|}{$\begin{array}{c}\text { Composite } \\
\text { Reliability (CR) }\end{array}$} & $\begin{array}{c}\text { Cronbach's } \\
\text { Alpha }\end{array}$ \\
\hline TSK & 0.832 & 0.908 & 0.801 \\
\hline TCH & 0.694 & 0.870 & 0.793 \\
\hline TTF & 0.715 & 0.881 & 0.792 \\
\hline PUF & 0.815 & 0.898 & 0.776 \\
\hline PEU & 0.708 & 0.877 & 0.787 \\
\hline GSUP & 0.870 & 0.930 & 0.853 \\
\hline SEC & 0.685 & 0.867 & 0.769 \\
\hline BINT & 0.667 & 0.855 & 0.740 \\
\hline
\end{tabular}

Table 4. Discriminant validity of measurement constructs (Fornell-Larcker criteria)

\begin{tabular}{|l|l|l|l|l|l|l|l|l|}
\hline \multicolumn{1}{|c|}{ Construct } & \multicolumn{1}{c|}{ TSK } & TCH & TTF & PEU & PUF & GSUP & SEC & BINT \\
\hline TSK & 0.912 & & & & & & & \\
\hline TCH & 0.710 & 0.833 & & & & & & \\
\hline TTF & 0.686 & 0.634 & 0.846 & & & & & \\
\hline PEU & 0.576 & 0.552 & 0.834 & 0.903 & & & & \\
\hline PUF & 0.678 & 0.553 & 0.842 & 0.806 & 0.841 & & & \\
\hline GSUP & 0.265 & 0.247 & 0.475 & 0.615 & 0.550 & 0.933 & & \\
\hline SEC & -0.452 & -0.416 & -0.758 & -0.840 & -0.759 & -0.799 & 0.828 & \\
\hline BINT & 0.491 & 0.420 & 0.750 & 0.844 & 0.777 & 0.840 & -0.759 & 0.817 \\
\hline
\end{tabular}

\subsection{Structural Model}

PLS-SEM path analysis method was employed for the structural model relationship assessment. The path coefficient and its significance were calculated, as shown in Table 5.

H1 tested TSK influence on TTF. The analysis of the data revealed that TSK significantly influences TTF. Hence, H1 is accepted, which conforms to prior research results that have shown TSK positively impacted TTF (Chen, 2019; Chang et al., 2016; Yadegaridehkordi et al., 2016; Ma et al., 2013; Tariq \& Akter, 2011). This result suggests that blood bank TSK such as ad-hoc blood unit demands and interdependence between various health departments provide a suitable fit for the adoption of technology.

$\mathrm{H} 2$ tested the TCH effect on TTF, and the analysis indicated that TCH significantly affect TTF. Hence, $\mathrm{H} 2$ is also supported. This finding is in line with the prior research in that previous results have also demonstrated a positive relationship between TCH and TTF (Wu \& Chen, 2017; Yadegaridehkordi et al., 2016; Tariq \& Akter, 2011; Yen et al., 2010). This result implies that Blockchain and IoT technology characteristics such as information accuracy, traceability, and reliability match with the blood bank operational requirements.

Further, results of the study also unveiled that TTF significantly affects PUF, which indicates that Blockchain and IoT enabled BBMIS will lead to perceived performance improvements in blood bank operations. Thus, H3 is accepted and confirms that TTF positively affects PUF, as evidenced in 
Table 5. Hypothesis testing results and structural relationships

\begin{tabular}{|c|c|c|c|c|c|}
\hline Hypothesis & Path & $\begin{array}{c}\text { Path } \\
\text { coefficient }\end{array}$ & $\begin{array}{c}\text { Standard } \\
\text { error }\end{array}$ & $t$ Statistics & $\begin{array}{c}\text { Hypothesis } \\
\text { Decision }\end{array}$ \\
\hline H1 & TSK $®$ TTF & 0.476 & 0.094 & $5.071 * * *$ & Supported \\
\hline $\mathrm{H} 2$ & $\mathrm{TCH} @ \mathrm{TTF}$ & 0.297 & 0.096 & $3.090 * * *$ & Supported \\
\hline H3 & TTF $®$ PUF & 0.596 & 0.116 & $5.116^{* * * *}$ & Supported \\
\hline $\mathrm{H} 4$ & TTF $®$ PEU & 0.884 & 0.020 & $3.561 * * *$ & Supported \\
\hline H5 & PEU ® PUF & 0.279 & 0.121 & $2.315^{* *}$ & Supported \\
\hline H6 & PEU ® BINT & 0.120 & 0.054 & $2.207 * *$ & Supported \\
\hline H7 & PUF $®$ BINT & 0.099 & 0.041 & $2.422 * *$ & Supported \\
\hline H8 & GSUP ® BINT & 0.239 & 0.077 & $3.088 * * *$ & Supported \\
\hline H9 & SEC $®$ BINT & -0.593 & 0.076 & $7.851 * * *$ & Supported \\
\hline
\end{tabular}

prior research (Chen, 2019; Daradkeh, 2019; Wu \& Chen, 2017; Yen et al., 2010). Similarly, results of the study indicated that TTF significantly affects PEU, which implies that Blockchain and IoT enabled BBMIS will be easy to use with no significant learning efforts. Thus, H4 is supported, which follows the prior research results with a positive relationship between TTF and PEU (Chang et al., 2016; Chen, 2019; Daradkeh, 2019; Ma et al., 2013; Vanduhe, Nat \& Hasan, 2020).

H5 tested the relationship between PEU and PUF. The analysis unveiled that PEU significantly affects PUF. Hence, H5 is supported, which confirms that an easy to use Blockchain and IoT based BBMIS will lead to higher perceived benefits of such a system. This finding conforms to prior research outcomes in that PEU has positively affected PUF (Daradkeh, 2019; Ma et al., 2013; Wu \& Chen, 2017; Yen et al., 2010). H6 tested PEU's impact on BINT. The analysis results suggested that PEU significantly influences BINT, implying that the blood bank stakeholders intend to embrace the Blockchain and IoT enabled BBMIS only when it is convenient to use. Hence, H6 is accepted, which follows the prior research outcomes demonstrating a positive relationship between PEU and BINT (Daradkeh, 2019; Ma et al., 2013; Wu \& Chen, 2017; Yen et al., 2010).

The analysis also unveiled that PUF significantly affects BINT, implying that an improved perceived performance of BBMIS will lead to positive BINT to adopt Blockchain and IoT based systems. Thus, H7 is supported and confirms that PUF positively affects BINT, as shown in prior research outcomes (Chang et al., 2016; Chen, 2019; Daradkeh, 2019; Ma et al., 2013).

Finally, the data analysis indicated that GSUP significantly affects BINT, suggesting strong governmental support will lead to higher BINT to use Blockchain and IoT enabled BBMIS. Thus, H8 is supported, which conforms to prior research expectations in a positive relationship between GSUP and BINT (Chiu et al., 2017; Lian et al., 2014; Lin \& Ho, 2008; Luthra et al., 2011; Rowe et al., 2012). As well, the study analyzed the role of SEC on BINT. The data analysis unveiled that SEC has a significant negative effect on BINT, and thus H9 is also accepted. The negative path coefficient indicates that security concerns act as an inhibitor to BINT to use Blockchain and IoT based BBMIS. This result confirms that SEC negatively affects BINT, as shown in the previous research (Al- Sharafi, Arshah, Abo-Shanab \& Elayah, 2016; Enaizan et al., 2018; Oliveira, Thomas, Baptista \& Campos, 2016; Rahi \& Abd. Ghani, 2018).

The overall findings (Figure 2) indicate that Blockchain and IoT are suitable IT solutions for a sustainable national blood bank system in India, which aligns with the WHO recommendations and justifies the unique contribution of this paper. 


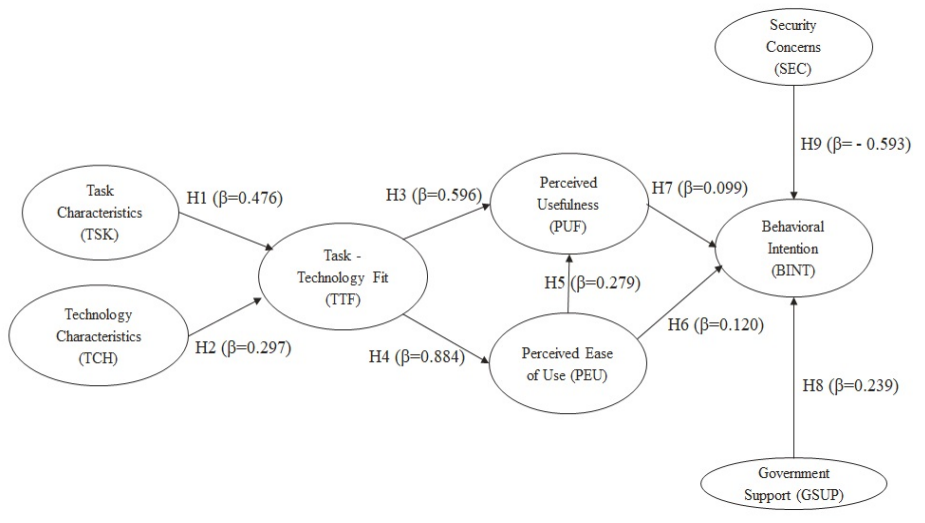

\section{DISCUSSION}

The PLS-SEM analysis of the data has shown that the conceptualized model variables TSK and TCH have a positive influence on the TTF as postulated by Task-Technology Fit theory. More specifically, the study results also unveiled that there is a positive relationship between TTF \& PUF and TTF \& PEU; moreover, PUF, PEU \& GSUP positively affect, whereas SEC negatively affects, the BINT. A positive relationship between TSK and TTF demonstrated that blood bank coordination tasks frequently deal with new types of scenarios and involve more than a single legal entity. TCH having a significant effect on TTF affirms that the Blockchain and IoT technology characteristics help in providing real-time, automated, and immutable information to remote stakeholders. As well, TTF significantly affects PUF and PEU, indicating that users perceive that Blockchain and IoT technologies are suitable IT solutions for various blood bank tasks, including collection, storage, monitor, and dispatch of the blood products.

According to TAM, PUF has a positive effect on BINT, which confirms that Blockchain and IoT based BBMIS will potentially improve the efficiency and productivity of blood bank stakeholders. That PEU has a positive influence on BINT supports the assumption that the Blockchain and IoT enabled BBMIS can be adopted without a lot of difficulties among end-users. The finding that GSUP will have a positive influence on BINT confirms that strong governmental support would be necessary for a higher adoption of new IT solutions. Last, the SEC construct having a negative effect on BINT implies that higher security concerns would lead to a lower adoption of the Blockchain and IoT enabled BBMIS.

Based on the aforementioned outcomes, the authors of this research paper propose a novel BBMIS solution comprising Blockchain and IoT technologies (see Figure 3). The solution depicts an IoT temperature sensor embedded in the cold storage unit of a blood bank. The IoT sensor can alert the blood bank staff on their mobile device in case of power failure or abnormal temperature variations. The IoT and blood unit stock data is stored on the blood bank server.

Each blood bank and a hospital can then be connected to a national blood bank Blockchain network to manage at the municipal (city) or state level demand-supply gap in real-time. The government's health department can maintain and monitor the Blockchain network and regulate the blood banks digitally to promote improved e-governance. Only those authorized and registered blood banks and hospitals should be able to perform Blockchain write-transactions. Initially, therefore, it is proposed to have a permissioned Blockchain network. Consensus algorithms such as Practical Byzantine Fault Tolerance may be configured for transaction processing instead of other costly proof-of-work like 

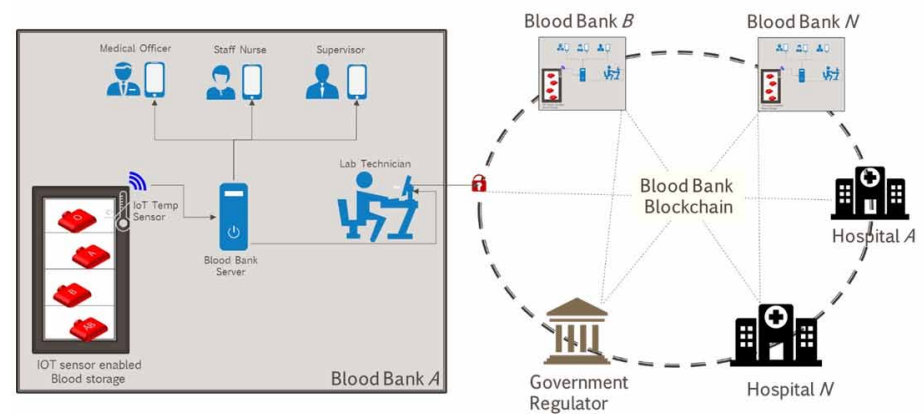

consensus algorithms. Being a permissioned Blockchain network, the transaction throughput will be much higher than its slower public Blockchain counterparts.

\subsection{Theoretical Contributions}

Overall, the study enhances our understanding of critical factors affecting emerging IT adoption for healthcare services in a developing country such as India.

More specifically, the study enhances the IT adoption and blood bank management literature. First, the research emphasizes a joint TTF-TAM framework to provide better explanatory power in measuring the IT adoption intention, which validates similar efforts in prior research work, while TAM remains a reliable model in studying IT adoption problems with the current study validating the application of TAM key constructs to the BBMIS.

Second, the study examines the TTF model application within the context of blood banks. The fit between the technology and task characteristics affirms that the blood bank related activities are suitable for emerging IT, namely, Blockchain and IoT. The study also highlights that latent variables of TTF, namely, performance impacts and utilization, may be mapped onto PUF and PEU of TAM respectively.

Finally, the study uniquely combines GSUP with TAM theory as an additional IT adoption predictor for services that are regulated by government agencies. The research also validates that SEC negatively influences BINT, implying users' IT adoption intention increases as security concern decreases.

\subsection{Managerial Implications}

From a practical perspective, the study results demonstrate that blood bank managers and healthcare professionals perceive Blockchain and IoT technologies have the right task-technology fit with BBMIS. Such a system would be beneficial for carrying out daily blood bank activities.

On the IoT front, the technology provides real-time status monitoring capability of physical objects to users ubiquitously, as discussed in term of tracking blood unit storage. Here, the blood bank staff would be immediately alerted if and when there is a breakdown in the blood storage equipment. As well, IoT can assist in the increased automation of various blood bank activities. Predictive analytics of the IoT data can project needed maintenance of critical equipment, reducing unforeseen machine failures. This capability would then lead to better asset management, cost optimization, and decision making for blood bank managers. Apparently, unauthorized access to the blood bank storage can also be prevented with IoT sensors, thereby improving the physical security of blood bank premises. In sum, we believe IoT play a valuable role in maximizing the shelf life and minimizing the wastage of accumulated blood units. 
Likewise, Blockchain brings multiple benefits to blood bank stakeholders. It acts as a single truth of data and removes the duplicate manual efforts in reconciliation among the various stakeholders. The proposed blood bank Blockchain network can show real-time blood bank stock inventory to patients and hospitals at the district, state, and national level. This is especially useful for finding the availability of rare blood group stock in emergencies. With increased transparency, stakeholders of the blood SC would then be able to plan blood donation camps as per the prevailing supply and demand gaps. Moreover, every transaction related to each blood unit will be sequentially recorded on the Blockchain. This chain of transactions would then help medical staff establish traceability before transfusing to the patient. And the tamper-proof nature of Blockchain records will provide increased resistance to any data manipulation attempts. Subsequently, the stringent regulatory audit process of blood banks will become much easier for all. Additionally, the IoT devices can also be connected to the blockchain network through cryptographic infrastructure, making them more secure from hackers. In general, we expect that Blockchain would primarily improve the efficiency and security of the national blood SC network.

\section{CONCLUSION AND FUTURE RESEARCH DIRECTIONS}

This paper highlights that blood banks on a Blockchain network will be able to better serve patient needs with real-time visibility into blood inventory, especially during emergencies. The blood donation camps can be planned in a more coordinated manner so that only required blood units are collected instead of stocking up excess quantities. With shared and immutable digital records on Blockchain, the entire blood SC will become more transparent and hassle-free for blood bank stakeholders. Blockchain technology will also enable a quicker root-cause analysis of any quality-related issue leading to immediate corrective actions within the national level blood bank ecosystem.

The study demonstrates the application of an extended TTF-TAM framework for the adoption of emerging IT-based solutions in the context of perishable items SC. External constructs such as Government Support and Security Concerns, when added to theories such as the TTF and TAM, further assisted in our understanding of IT diffusion in particular contexts. Additionally, IoT technology would lead to better maintenance of blood bank equipment and can trigger appropriate response to avoid any blood unit wastage. Although the current study found that Blockchain and IoT technologies would be useful in overall blood SCM, there are few limitations to this study in terms of geography and actual implementation. The research data is only collected from healthcare professionals and blood bank managers based out of Pune metropolitan region in India. Caution needs to be exercised before generalizing the results to other geographies. As well, the research only studied the behavioral intention of Blockchain and IoT based blood bank management system. However, other constructs such as Technology Readiness, Social Influence, Actual Usage, and Customer Satisfaction may be investigated in future studies. Additionally, future researchers may explore various Blockchain consensus algorithms and IoT protocols to further improve performance of the national blood bank network.

Finally, the study underscores the importance of security of the IT solution. A more secure BBMIS would help blood bank staff to spend more time on their core activities rather than worrying about the system integrity. This entails IT architects to ensure the proposed solution has all the latest security aspects incorporated in it. Similarly, the study highlights that the Blockchain and IoT enabled BBMIS would digitize and streamline the audit process, which currently suffers from physical paper-based record management and susceptible to manipulations. The study highlights the role of government support in modifying related policies and regulations for higher adoption of emerging IT solutions. Accordingly, the government authorities need to plan and incentivize stakeholders of the blood supply chain. This would later assist the government in rolling out other emerging IT-based solutions as part of larger e-governance initiative. 


\section{REFERENCES}

Abarca, A., De la Fuente, M., Abril, J. M., García, A., \& Pérez-Ocón, F. (2009). Intelligent sensor for tracking and monitoring of blood temperature and hemoderivatives used for transfusions. Sensors and Actuators. A, Physical, 152(2), 241-247. doi:10.1016/j.sna.2009.03.018

Adams, D. A., Nelson, R. R., \& Todd, P. A. (1992). Perceived usefulness, ease of use, and usage of information technology: A replication. Management Information Systems Quarterly, 16(2), 227-247. doi:10.2307/249577

Ahram, T., Sargolzaei, A., Sargolzaei, S., Daniels, J., \& Amaba, B. (2017, June). Blockchain technology innovations. In 2017 IEEE Technology \& Engineering Management Conference (TEMSCON) (pp. 137-141). IEEE. doi:10.1109/TEMSCON.2017.7998367

Ajzen, I. (1985). From intentions to actions: A theory of planned behavior. In Action control (pp. 11-39). Springer. doi:10.1007/978-3-642-69746-3_2

Al-Sharafi, M. A., Arshah, R. A., Abo-Shanab, E. A., \& Elayah, N. (2016). The effect of security and privacy perceptions on customers' trust to accept internet banking services: An extension of TAM. Journal of Engineering and Applied Sciences (Asian Research Publishing Network), 11(3), 545-552.

Alemdar, H., \& Ersoy, C. (2010). Wireless sensor networks for healthcare: A survey. Computer Networks, 54(15), 2688-2710. doi:10.1016/j.comnet.2010.05.003

Alraimi, K. M., Zo, H., \& Ciganek, A. P. (2015). Understanding the MOOCs continuance. Computers \& Education, 80(80), 28-38. doi:10.1016/j.compedu.2014.08.006

Apte, S., \& Petrovsky, N. (2016). Will blockchain technology revolutionize excipient supply chain management? Journal of Excipients and Food Chemicals, 7(3), 910.

Arif, M., Sreevas, S., Nafseer, K., \& Rahul, R. (2012, December). Automated online Blood bank database. In 2012 Annual IEEE India Conference (INDICON) (pp. 012-017). IEEE. doi:10.1109/INDCON.2012.6420581

Armstrong, J. S., \& Overton, T. S. (1977). Estimating nonresponse bias in mail surveys. JMR, Journal of Marketing Research, 14(3), 396-402. doi:10.1177/002224377701400320

Ashton, K. (2009). That 'internet of things' thing. RFID Journal, 22(7), 97-114.

Batubara, F. R., Ubacht, J., \& Janssen, M. (2018, May). Challenges of blockchain technology adoption for e-government: a systematic literature review. In Proceedings of the 19th Annual International Conference on Digital Government Research: Governance in the Data Age (pp. 1-9). doi:10.1145/3209281.3209317

Ben-Daya, M., Hassini, E., \& Bahroun, Z. (2019). Internet of things and supply chain management: A literature review. International Journal of Production Research, 57(15-16), 4719-4742. doi:10.1080/00207543.2017.1 402140

Biswas, K., Muthukkumarasamy, V., \& Tan, W. L. (2017). Blockchain based wine supply chain traceability system. In Future Technologies Conference (FTC) (pp. 56-62). The Science and Information Organization.

Boonyanusith, W., \& Jittamai, P. (2017). Transforming blood supply chain management with Internet of things paradigm. In Digitalization in Supply Chain Management and Logistics: Smart and Digital Solutions for an Industry 4.0 Environment. Proceedings of the Hamburg International Conference of Logistics (pp. 139-156). Academic Press.

Briggs, L., Davis, R., Gutierrez, A., Kopetsky, M., Young, K., \& Veeramani, R. (2009). RFID in the blood supply chain-increasing productivity, quality and patient safety. Journal of Healthcare Information Management, 23(4), 54-63. PMID:19894488

Buse, K., \& Hawkes, S. (2015). Health in the sustainable development goals: Ready for a paradigm shift? Globalization and Health, 11(1), 13. doi:10.1186/s12992-015-0098-8 PMID:25890267

Chang, H. S., Lee, S. C., \& Ji, Y. G. (2016). Wearable device adoption model with TAM and TTF. International Journal of Mobile Communications, 14(5), 518-537. doi:10.1504/IJMC.2016.078726

Chen, N. (2019). Extending a TAM-TTF model with perceptions toward telematics adoption. Asia Pacific Journal of Marketing and Logistics, 31(1), 37-54. doi:10.1108/APJML-02-2018-0074 
Chiu, C. Y., Chen, S., \& Chen, C. L. (2017). An integrated perspective of TOE framework and innovation diffusion in broadband mobile applications adoption by enterprises. International Journal of Management Economics and Social Sciences, 6(1), 14-39.

Cho, Y. (2017). A consumer satisfaction model based on the integration of EDT and TAM: Comparative study of Korean and US consumers. Asia Pacific Journal of Marketing and Logistics, 29(5), 978-993. doi:10.1108/ APJML-07-2016-0127

Clauson, K., Breeden, E., Davidson, C., \& Mackey, T. (2018). Leveraging Blockchain Technology to Enhance Supply Chain Management in Healthcare. Blockchain in Healthcare Today, 1.

Dada, A., \& Thiesse, F. (2008). Sensor applications in the supply chain: the example of quality-based issuing of perishables. In The Internet of Things (pp. 140-154). Springer. doi:10.1007/978-3-540-78731-0_9

Daradkeh, M. (2019). Visual analytics adoption in business enterprises: An integrated model of technology acceptance and task-technology fit. International Journal of Information Systems in the Service Sector, 11(1), 68-89. doi:10.4018/IJISSS.2019010105

Davis, F. D. (1989). Perceived usefulness, perceived ease of use, and user acceptance of information technology. Management Information Systems Quarterly, 13(3), 319-340. doi:10.2307/249008

Davis, R., Geiger, B., Gutierrez, A., Heaser, J., \& Veeramani, D. (2009). Tracking blood products in blood centres using radio frequency identification: A comprehensive assessment. Vox Sanguinis, 97(1), 50-60. doi:10.1111/j.1423-0410.2009.01174.x PMID:19320963

Dawley, R. E. (1984). U.S. Patent No. 4,441,329. Washington, DC: U.S. Patent and Trademark Office.

Dishaw, M. T., \& Strong, D. M. (1999). Extending the technology acceptance model with task-technology fit constructs. Information \& Management, 36(1), 9-21. doi:10.1016/S0378-7206(98)00101-3

DOHFW. (2018). Annual Report 2017-18. Retrieved from https://www.mohfw.nic.in/sites/default/files/24Chapter. pdf

Düdder, B., \& Ross, O. (2017). Timber tracking reducing complexity of due diligence by using blockchain technology. Joint Proceedings of the BIR, 28-30.

Enaizan, O., Zaidan, A. A., Alwi, N. M., Zaidan, B. B., Alsalem, M. A., Albahri, O. S., \& Albahri, A. S. (2018). Electronic medical record systems: Decision support examination framework for individual, security and privacy concerns using multi-perspective analysis. Health and Technology, 1-28.

Erskine, M. A., Gregg, D. G., Karimi, J., \& Scott, J. E. (2019). Individual decision-performance using spatial decision support systems: A geospatial reasoning ability and perceived task-technology fit perspective. Information Systems Frontiers, 21(6), 1369-1384. doi:10.1007/s10796-018-9840-0

Farmer, J. J. (1982, November). A Blood Bank Information Management System. Proceedings of the Annual Symposium on Computer Application in Medical Care (pp. 287-290). American Medical Informatics Association.

Fishbein, M., \& Ajzen, I. (1980). Understanding attitudes and predicting social behavior. Prentice Hall.

Fornell, C., \& Larcker, D. F. (1981). Evaluating structural equation models with unobservable variables and measurement error. JMR, Journal of Marketing Research, 18(1), 39-50. doi:10.1177/002224378101800104

Gao, L., \& Bai, X. (2014). A unified perspective on the factors influencing consumer acceptance of the internet of things technology. Asia Pacific Journal of Marketing and Logistics, 26(2), 211-231. doi:10.1108/ APJML-06-2013-0061

Gefen, D., Straub, D., \& Boudreau, M. C. (2000). Structural equation modeling and regression: Guidelines for research practice. Communications of the Association for Information Systems, 4(1), 7. doi:10.17705/1CAIS.00407

GOI. (2003). Transfusion Medicine, Technical Manual. Director General of Health Services, Government of India.

Goodhue, D. L., \& Thompson, R. L. (1995). Task-technology fit and individual performance. Management Information Systems Quarterly, 19(2), 213-236. doi:10.2307/249689 
Grabner-Kräuter, S., \& Kaluscha, E. A. (2003). Empirical research in on-line trust: A review and critical assessment. International Journal of Human-Computer Studies, 58(6), 783-812. doi:10.1016/S10715819(03)00043-0

Gubbi, J., Buyya, R., Marusic, S., \& Palaniswami, M. (2013). Internet of Things (IoT): A vision, architectural elements, and future directions. Future Generation Computer Systems, 29(7), 1645-1660. doi:10.1016/j. future.2013.01.010

Gudergan, S. P., Ringle, C. M., Wende, S., \& Will, A. (2008). Confirmatory tetrad analysis in PLS path modeling. Journal of Business Research, 61(12), 1238-1249. doi:10.1016/j.jbusres.2008.01.012

Hair, J. F., Black, W. C., Babin, B. J., Anderson, R. E., \& Tatham, R. L. (2006). Multivariate data analysis (Vol. 6). Pearson-Prentice Hall.

Hair, J. F., Ringle, C. M., \& Sarstedt, M. (2011). PLS-SEM: Indeed a silver bullet. Journal of Marketing Theory and Practice, 19(2), 139-152. doi:10.2753/MTP1069-6679190202

Heeks, R. (Ed.). (2001). Reinventing government in the information age: International practice in IT-enabled public sector reform (Vol. 1). Psychology Press.

Henseler, J. (2010). On the convergence of the partial least squares path modeling algorithm. Computational Statistics, 25(1), 107-120. doi:10.1007/s00180-009-0164-x

Herath, T., \& Rao, H. R. (2009). Encouraging information security behaviors in organizations: Role of penalties, pressures and perceived effectiveness. Decision Support Systems, 47(2), 154-165. doi:10.1016/j.dss.2009.02.005

Hess, J. R. (2010). Conventional blood banking and blood component storage regulation: Opportunities for improvement. Blood Transfusion, 8(3), 9-15. PMID:20606757

Hohberger, C., Davis, R., Briggs, L., Gutierrez, A., \& Veeramani, D. (2012). Applying radio-frequency identification (RFID) technology in transfusion medicine. Biologicals, 40(3), 209-213. doi:10.1016/j. biologicals.2011.10.008 PMID:22079476

Hong, J. Y., Suh, E. H., \& Kim, S. J. (2009). Context-aware systems: A literature review and classification. Expert Systems with Applications, 36(4), 8509-8522.

Hsu, C. W., \& Yeh, C. C. (2017). Understanding the factors affecting the adoption of the Internet of Things. Technology Analysis and Strategic Management, 29(9), 1089-1102. doi:10.1080/09537325.2016.1269160

Jayaraman, R., Saleh, K., \& King, N. (2019). Improving Opportunities in healthcare supply chain processes via the Internet of Things and Blockchain Technology. International Journal of Healthcare Information Systems and Informatics, 14(2), 49-65. doi:10.4018/IJHISI.2019040104

Karahanna, E., \& Straub, D. W. (1999). The psychological origins of perceived usefulness and ease-of-use. Information \& Management, 35(4), 237-250. doi:10.1016/S0378-7206(98)00096-2

Koufaris, M. (2002). Applying the technology acceptance model and flow theory to online consumer behavior. Information Systems Research, 13(2), 205-223. doi:10.1287/isre.13.2.205.83

Lee, D. Y., \& Lehto, M. R. (2013). User acceptance of YouTube for procedural learning: An extension of the Technology Acceptance Model. Computers \& Education, 61, 193-208. doi:10.1016/j.compedu.2012.10.001

Lee, Y., Kozar, K. A., \& Larsen, K. R. (2003). The technology acceptance model: Past, present, and future. Communications of the Association for Information Systems, 12(50), 752-780. doi:10.17705/1CAIS.01250

Lee, Y. H., Hsieh, Y. C., \& Chen, Y. H. (2013). An investigation of employees' use of elearning systems: Applying the technology acceptance model. Behaviour \& Information Technology, 32(2), 173-189. doi:10.10 80/0144929X.2011.577190

Lewis, E. F., Hardy, M., \& Snaith, B. (2013). An analysis of survey reporting in the imaging professions: Is the issue of non-response bias being adequately addressed? Radiography, 19(3), 240-245. doi:10.1016/j. radi.2013.02.003 
Lian, J. W., Yen, D. C., \& Wang, Y. T. (2014). An exploratory study to understand the critical factors affecting the decision to adopt cloud computing in Taiwan hospital. International Journal of Information Management, 34(1), 28-36. doi:10.1016/j.ijinfomgt.2013.09.004

Lin, C. Y., \& Ho, Y. H. (2008). An empirical study on logistics service providers' intention to adopt green innovations. Journal of Technology Management \& Innovation, 3(1), 17-26.

Lin, I. C., \& Liao, T. C. (2017). A Survey of Blockchain Security Issues and Challenges. International Journal of Network Security, 19(5), 653-659.

Lowalekar, H., \& Ravi, R. R. (2017). Revolutionizing blood bank inventory management using the TOC thinking process: An Indian case study. International Journal of Production Economics, 186, 89-122. doi:10.1016/j. ijpe.2017.02.003

Lowalekar, H., \& Ravichandran, N. (2014). Blood bank inventory management in India. Opsearch, 51(3), 376-399. doi:10.1007/s12597-013-0148-z

Luthra, S., Kumar, V., Kumar, S., \& Haleem, A. (2011). Barriers to implement green supply chain management in automobile industry using interpretive structural modeling technique: An Indian perspective. Journal of Industrial Engineering and Management, 4(2), 231-257. doi:10.3926/jiem.2011.v4n2.p231-257

Ma, C. M., Chao, C. M., \& Cheng, B. W. (2013). Fit into Blended E-learning System. Journal of Applied Sciences, 13(5), 736-742. doi:10.3923/jas.2013.736.742

MacKenzie, S. B., \& Podsakoff, P. M. (2012). Common method bias in marketing: Causes, mechanisms, and procedural remedies. Journal of Retailing, 88(4), 542-555. doi:10.1016/j.jretai.2012.08.001

MacKenzie, S. B., Podsakoff, P. M., \& Podsakoff, N. P. (2011). Construct measurement and validation procedures in MIS and behavioral research: Integrating new and existing techniques. Management Information Systems Quarterly, 35(2), 293-334. doi:10.2307/23044045

McCole, P., Ramsey, E., \& Williams, J. (2010). Trust considerations on attitudes towards online purchasing: The moderating effect of privacy and security concerns. Journal of Business Research, 63(9-10), 1018-1024. doi:10.1016/j.jbusres.2009.02.025

Menachemi, N. (2011). Assessing response bias in a web survey at a university faculty. Evaluation and Research in Education, 24(1), 5-15. doi:10.1080/09500790.2010.526205

Michie, S., \& Marteau, T. (1999). Non-response bias in prospective studies of patients and health care professionals. International Journal of Social Research Methodology, 2(3), 203-212. doi:10.1080/136455799295014

NACO. (2016). Assessment of Blood Banks In India - 2016. Retrieved from http://naco.gov.in/sites/default/files/ Assessment\%20of\%20Blood\%20Banks\%20in\%20India\%20-\%202016.pdf

NACO. (2017). Data of discarded units. Retrieved from http://naco.gov.in/sites/default/files/DATA\%20OF\%20 DISCARDED\%20UNITS.pdf

Nakamoto, S. (2008). Bitcoin: A peer-to-peer electronic cash system. Retrieved from https://bitcoin.org/bitcoin.pdf

Nanu, A. (2001). Blood transfusion services: Organization is integral to safety. The National Medical Journal of India, 14(4), 237-240. PMID:11547532

Nunnally, J. C. (1978). Psychometric Theory (2nd ed.). McGraw-Hill.

Oliveira, T., Thomas, M., Baptista, G., \& Campos, F. (2016). Mobile payment: Understanding the determinants of customer adoption and intention to recommend the technology. Computers in Human Behavior, 61, 404-414. doi:10.1016/j.chb.2016.03.030

Ølnes, S., Ubacht, J., \& Janssen, M. (2017). Blockchain in Government: Benefits and implications of distributed ledger technology for information sharing. Government Information Quarterly, 34(3), 355-364. doi:10.1016/j. giq.2017.09.007

Pal, R., Kar, S., Zaman, F. A., \& Pal, S. (2011). The quest for an Indian blood law as of blood transfusion services regulatory framework. Asian Journal of Transfusion Science, 5(2), 171-174. doi:10.4103/0973-6247.83246 PMID:21897599 
Peltoniemi, T., \& Ihalainen, J. (2019). Evaluating Blockchain for the Governance of the Plasma Derivatives Supply Chain: How Distributed Ledger Technology Can Mitigate Plasma Supply Chain Risks. Blockchain in Healthcare Today, 2.

Peoples, C., Parr, G., McClean, S., Scotney, B., \& Morrow, P. (2013). Performance evaluation of green data centre management supporting sustainable growth of the internet of things. Simulation Modelling Practice and Theory, 34, 221-242. doi:10.1016/j.simpat.2012.12.008

Pierskalla, W. P. (2005). Supply chain management of blood banks. In Operations research and health care. Springer.

Pietersz, R. N. I. (1995). Automation/computerization in blood processing. Transfusion Science, 16(3), 235-241. doi:10.1016/0955-3886(95)00028-V PMID:10159878

Queiroz, M. M., \& Wamba, S. F. (2019). Blockchain adoption challenges in supply chain: An empirical investigation of the main drivers in India and the USA. International Journal of Information Management, 46, 70-82. doi:10.1016/j.ijinfomgt.2018.11.021

Rahi, S., \& Abd. Ghani, M. (2018). The role of UTAUT, DOI, perceived technology security and game elements in internet banking adoption. World Journal of Science. Technology and Sustainable Development, 15(4), 338-356.

Raj, J., \& Tarun, S. (1991). Storing crossmatched blood: A perishable inventory model with prior allocation. Management Science, 37(3), 251-266. doi:10.1287/mnsc.37.3.251

Ramani, K. V., Mavalankar, D., \& Govil, D. (2007). Management of blood transfusion services in India: An illustrative study of Maharashtra and Gujarat States. Retrieved from http://vslir.iima.ac.in:8080/jspui/ bitstream/11718/5944/1/2007-03-09_kvramani.pdf

Ringle, C. M., Wende, S., \& Will, A. (2005). SmartPLS, 2.0 (Beta ed). Hamburg, Germany: Academic Press.

Rowe, F., Truex, D., \& Huynh, M. Q. (2012). An empirical study of determinants of e-commerce adoption in SMEs in Vietnam: An economy in transition. Journal of Global Information Management, 20(3), 23-54. doi:10.4018/jgim.2012070102

Scupola, A. (2003). The adoption of Internet commerce by SMEs in the south of Italy: An environmental, technological and organizational perspective. Journal of Global Information Technology Management, 6(1), 52-71. doi:10.1080/1097198X.2003.10856343

Shih, C. W., \& Wang, C. H. (2016). Integrating wireless sensor networks with statistical quality control to develop a cold chain system in food industries. Computer Standards \& Interfaces, 45, 62-78. doi:10.1016/j.csi.2015.12.004

Sinha, A., Kumar, P., Rana, N. P., Islam, R., \& Dwivedi, Y. K. (2019). Impact of internet of things (IoT) in disaster management: A task-technology fit perspective. Annals of Operations Research, 283(1-2), 759-794. doi:10.1007/s10479-017-2658-1

Sulaiman, S., Hamid, A. A. K. A., \& Yusri, N. A. N. (2015). Development of a blood bank management system. Procedia: Social and Behavioral Sciences, 195, 2008-2013. doi:10.1016/j.sbspro.2015.06.215

Tariq, A., \& Akter, S. (2011). An assessment of m-Health in developing countries using task technology fit model. In AMCIS 2011 Proceedings Association for Information Systems (pp. 1-12). Academic Press.

Taylor, R., Bower, A., Girosi, F., Bigelow, J., Fonkych, K., \& Hillestad, R. (2005). Promoting health information technology: Is there a case for more-aggressive government action? Health Affairs, 24(5), 1234-1245. doi:10.1377/ hlthaff.24.5.1234 PMID:16162568

Tian, F. (2016, June). An agri-food supply chain traceability system for China based on RFID \& blockchain technology. In 2016 13th international conference on service systems and service management (ICSSSM) (pp. 1-6). IEEE.

Tornatzky, L. G., Fleischer, M., \& Chakrabarti, A. K. (1990). Processes of technological innovation. Lexington Books.

Tse, D., Zhang, B., Yang, Y., Cheng, C., \& Mu, H. (2017, December). Blockchain application in food supply information security. 2017 IEEE International Conference on Industrial Engineering and Engineering Management (IEEM) (pp. 1357-1361). IEEE. doi:10.1109/IEEM.2017.8290114 
Turk, Ž., \& Klinc, R. (2017). Potentials of blockchain technology for construction management. Procedia Engineering, 196, 638-645. doi:10.1016/j.proeng.2017.08.052

UNDP. (2017). UNDP support to the implementation of sustainable development goal 3. Retrieved from http:// www.undp.org/content/dam/undp/library/Sustainable\%20Development/SDG-3\%20Health.pdf

Vanduhe, V. Z., Nat, M., \& Hasan, H. F. (2020). Continuance Intentions to Use Gamification for Training in Higher Education: Integrating the Technology Acceptance Model (TAM), Social Motivation, and Task Technology Fit (TTF). IEEE Access: Practical Innovations, Open Solutions, 8, 21473-21484. doi:10.1109/ ACCESS.2020.2966179

Venkatesh, V., \& Davis, F. D. (2000). A theoretical extension of the technology acceptance model: Four longitudinal field studies. Management Science, 46(2), 186-204. doi:10.1287/mnsc.46.2.186.11926

Verdouw, C. N., Wolfert, J., Beulens, A. J. M., \& Rialland, A. (2016). Virtualization of food supply chains with the internet of things. Journal of Food Engineering, 176, 128-136. doi:10.1016/j.jfoodeng.2015.11.009

Weber, R. H. (2009). Internet of things-Need for a new legal environment? Computer Law \& Security Review, 25(6), 522-527. doi:10.1016/j.clsr.2009.09.002

Welbourne, E., Battle, L., Cole, G., Gould, K., Rector, K., Raymer, S., Balazinska, M., \& Borriello, G. (2009). Building the internet of things using RFID: The RFID ecosystem experience. IEEE Internet Computing, 13(3), 48-55. doi:10.1109/MIC.2009.52

WHO. (2008). Universal Access to Safe Blood Transfusion. Retrieved from http://apps.who.int/iris/ handle/10665/69747

WHO. (2011). Developing a National Blood System. Retrieved from https://www.who.int/entity/bloodsafety/ publications/am_developing_a_national_blood_system.pdf?ua=1

WHO. (2016). The global need for safe blood. Retrieved from https://www.who.int/worldblooddonorday/ campaignkit/WBDD_GlobalNeed_English.pdf

Wong, K. F. (2011). Virtual blood bank. Journal of Pathology Informatics, 2(1), 6. doi:10.4103/2153-3539.76155 PMID:21383930

Wu, B., \& Chen, X. (2017). Continuance intention to use MOOCs: Integrating the technology acceptance model (TAM) and task technology fit (TTF) model. Computers in Human Behavior, 67, 221-232. doi:10.1016/j. chb.2016.10.028

Wu, B., \& Zhang, C. Y. (2014). Empirical study on continuance intentions towards ELearning 2.0 systems. Behaviour \& Information Technology, 33(10), 1027e1038.

Xu, W., Lian, Z., \& Yao, X. (2013, December). Integrating RFID with blood supply chain: A Technical and Business Analysis. In 2013 IEEE International Conference on Industrial Engineering and Engineering Management (pp. 1087-1091). IEEE. doi:10.1109/IEEM.2013.6962578

Yadegaridehkordi, E., Iahad, N. A., \& Ahmad, N. (2016). Task-technology fit assessment of cloud-based collaborative learning technologies. International Journal of Information Systems in the Service Sector, 8(3), 58-73. doi:10.4018/IJISSS.2016070104

Yen, D. C., Wu, C. S., Cheng, F. F., \& Huang, Y. W. (2010). Determinants of users' intention to adopt wireless technology: An empirical study by integrating TTF with TAM. Computers in Human Behavior, 26(5), 906-915. doi:10.1016/j.chb.2010.02.005 
Sachin Kuberkar is currently a research scholar at Symbiosis International University, Pune. His research interests include emerging technology and has expertise in Blockchain, IoT and Data Analytics. He has over 18 years of experience in Information Technology industry. He has managed and led many large-scale software programs for banking, logistics and healthcare clients. He has performed various roles starting from software engineer to principal consultant in the IT services industry. He has received his Executive MBA degree from Pune University and BE degree from National Institute of Technology Karnataka.

Tarun Kumar Singhal is presently working as Professor (IT Management) with Symbiosis Centre for Management Studies, Noida (UP) (Constituent of Symbiosis International University (Deemed), Pune). He is also contributing as Honorary Member at Centre of Excellence (CoE) in IT Enabled Services (ITES) Vertical established by Tata Institute of Social Sciences (TISS) School of Vocational Education (SVE), Mumbai. He holds PhD Degree in Business Administration and master's degrees in Software Systems as well as Mathematics. He has sound knowledge of framework for holistic development of professional institutions. He has been involved in number of third party assignments in the capacity of Consultant for Software Project Management, Establishment \& Development of Institutions of Excellence, Preparation of Feasibility Report for Institutions, Training the Trainers, ISO 9001 System, Team Building \& Leadership Development, Web Based Solutions, BPO Operations, Establishment of Software Development Center and Selection of Competent Personnel. He is associated as member of the board of referees/reviewers for the Amity Business Review (ABR), Amity Journal of Computational Sciences (AJCS), Advances in Science, Technology and Engineering Systems Journal (ASTESJ), International Journal of Strategic Business Alliances (IJSBA). 